\title{
Lessons on non-progression of HIV disease from monkeys
}

\author{
Pramod N. Nehete ${ }^{1}$, Shailbala Singh ${ }^{2}$ and K. Jagannatha Sastry ${ }^{1,2 *}$ \\ 1 Department of Veterinary Sciences, The University of Texas MD Anderson Cancer Center, Bastrop, TX, USA \\ 2 Department of Immunology, The University of Texas MD Anderson Cancer Center, Houston, TX, USA \\ *Correspondence: jsastry@mdanderson.org
}

Edited by:

Nitin K. Saksena, Westmead Millennium Institute, Australia

Reviewed by:

Nitin K. Saksena, Westmead Millennium Institute, Australia

Rhesus macaques infected with simian immunodeficiency virus (SIV) represent the most widely used model for studies related to understanding infection, pathology, immunology, and intervention strategies for HIV infection and AIDS in humans. This model recapitulates the significant impact of host immunogenetics and interindividual variations on the natural disease course of HIV-AIDS in humans. In addition to the parallel kinetics for fast- and slow-progressing disease course observed in majority of animals, a small subset of animals exhibit long-term non-progression (LTNP) or elite control (EC) status defined as low to undetectable viral loads in the absence of any interventions for prolonged periods. Therefore, the rhesus macaque model has been and continues to be the most extensively adopted experimental system for studies to not only confirm observations from HIV-ADIS in humans but also to validate several mechanistic features of the infection and disease course, which otherwise would be impractical and immoral to be performed in humans.

The natural EC of HIV- 1 in humans and of SIV in rhesus macaques has been attributed to the contributions of variety of host and viral factors (Betts et al., 2006; Saksena et al., 2007; Freel et al., 2010). Virus-specific $\mathrm{CD}^{+} \mathrm{T}$ helper cells are central for maintaining effective immunity in case of a number of chronic viral infections including HIV, where infected individuals that control viremia in the absence of antiviral therapy exhibit persistent and vigorous HIV-specific $\mathrm{CD}^{+} \mathrm{T}$ cell responses, in particular to the viral core protein p24 that display polyfunctionality in terms of secreting multiple cytokines and chemokines (Kalams and Walker, 1998). Employing the SIV-rhesus model, Louis Picker's group showed that strong and early containment in terms of undetectable plasma viral loads as well as prolonged protection against pathogenic SIV challenge in monkeys immunized with SIV DNA delivered by employing rhesus CMV and Adenoviral vectors correlated with high frequencies of virus-specific effector memory $\mathrm{CD}^{+} \mathrm{T}$ cell responses within the potential sites of SIV replication (Hansen et al., 2011). In our lab, studies testing peptide-based vaccine (Nehete et al., $1998,2001,2005,2008)$ and adenovirus vectored vaccines (Mercier et al., 2007; Weaver et al., 2009) against systemic or mucosal challenge with different strains of simian human immunodeficiency viruses (SHIV ku2, SHIV89p, and SHIV 162p3), revealed strong correlation for virus control, to undetectable levels in significant population of animals, preferentially with antigen specific cellular immune responses $\left(\mathrm{CD}^{+}\right.$and $\mathrm{CD} 8^{+} \mathrm{T}$ cells). We also assessed functional characteristics of memory T cells subsets as potential prognostic markers for changing viral loads and/or disease progression using the SHIV-infected rhesus macaque model and observed that functional impairment of $\mathrm{CD}^{+} \mathrm{T}$ cells in general, and of central memory subset in particular, may be a potential indicator/predictor of chronic infection with immune dysfunction, which could be assayed relatively easily using non-specific PMA + I stimulation (He et al., 2011).

Two other immune cell types recognized for potential contributions to influence virus control in SIV infected rhesus macaques and HIV-infected humans include $\mathrm{CD} 4^{+} \mathrm{T}$ cells subsets that either produce IL-17, Th17 cells, or exert immunosuppressive function, $\mathrm{CD}_{25}{ }^{+} \mathrm{FoxP}^{+}$regulatory $\mathrm{T}$ cells or $\mathrm{T}$-reg (Cecchinato and Franchini, 2010). Depletion of Th17 cells in humans as well as macaques, relatively soon after virus exposure, has been associated with the dissemination of microbial products from the infected gut, thereby adding to the systemic immune activation and disease progression. On the other hand, T-regs have been associated with compromised antiviral $\mathrm{T}$ cell responses. Substantive studies in the non-human primates combined with epidemiological observations in humans suggest that both these cells subsets, through influencing innate and adaptive immune responses, significantly impact the inflammatory milieu of the host to ultimately affect the outcome of the immunodeficiency virus infection (Favre et al., 2009; Dandekar et al., 2010; Kanwar et al., 2010).

Clinically healthy HIV-infected individuals that maintain stable high $\mathrm{CD} 4^{+} \mathrm{T}$ cell counts also exhibit strong and early onset of anti-HIV $\mathrm{CD}^{+} \mathrm{T}$ cell responses pointing to their protective role, which prompted elegant experiments that tested in vivo $\mathrm{CD} 8^{+} \mathrm{T}$ cell depletion in SIV infected rhesus macaques demonstrating the critical role of these immune cells in the early control of infection (Deeks and Walker, 2007; Freel et al., 2010). While the role of $\mathrm{CD}^{+}$ $\mathrm{T}$ cells in cell-mediated immunity is manifested in terms of production of a variety of cytokines, $\mathrm{CD} 8^{+} \mathrm{T}$ cells are more frequently recognized for their cytolytic property even though they are capable of multiple functions that include production of a variety of cytokines and soluble factors to restrict viral replication in infected cells (Buchbinder et al., 2008). In this regard, Watkins group (Goulder and Watkins, 2004) using in vitro assays based on cytokine production by the $\mathrm{CD}^{+} \mathrm{T}$ cells demonstrated suppression of viral replication and also showed that $\mathrm{CD} 8^{+}$ $\mathrm{T}$ cell clones, from monkeys in the elite SIV control group, recognizing the same epitope differ significantly in their capacity to suppress SIV replication. These studies further demonstrated that the in vitro efficacy of the $\mathrm{CD} 8^{+} \mathrm{T}$ cells to suppress virus replication is not necessarily tied always to production of cytokine most commonly assayed, such as IFN- $\gamma$, TNG- $\alpha$, or IL-2 (Goulder and Watkins, 2004). 
The unique strength of the virusspecific $\mathrm{CD}^{+} \mathrm{T}$ cell immunity for virus control in LTNP and EC has been most widely elaborated in the literature to be associated with host genetic factors, specifically expression of certain class I major histocompatibility complex (MHC-1) alleles (Migueles et al., 2000; Fellay et al., 2009). It has been well recognized that individuals expressing HLA-B27- and - B57 alleles are among the elite controllers of HIV replication, implying that $\mathrm{CD}^{+} \mathrm{T}$ cell responses restricted by these host genes exert potent anti-HIV effects. Analogous to these observations are studies in the SIV-rhesus model demonstrating that animals expressing $\mathrm{Mamu-} A^{*} 001$ and Mamu-B*08 exhibit low to undetectable viral loads without experimental interventions, so much so that $50 \%$ of Mamu-B*08-positive rhesus macaques of Indian origin were shown to effectively control SIVmac239 replication to become EC (Loffredo et al., 2008). Such parallels between human and rhesus MHC alleles contributing for virus control, defined as significantly lower set-point viral load and prolonged survival time, were noted specifically for HLA-B*14, and -B*57 in humans and Mamu-A*001, $A^{*} 002, A^{*} 008$, $A^{*} 011 ; B^{*} 001, B^{*} 003, B^{*} 004, B^{*} 008, B^{*} 017$, $B^{*} 029, \quad D R B^{*} w 201, \quad D R B 1^{*} 0401 / 06 / 11$, and $D P B 1^{*} 06$ in macaques (Goulder and Watkins, 2008). The most compelling evidence, beyond the genetic linkage studies, for the contribution of host immune responses restricted by specific MHC alleles is presented in recent studies from the Watkin's group (Mudd et al., 2012). In this study, Mamu- $B^{*} 08$ expressing rhesus macaques when vaccinated with three peptide sequences restricted by Mamu-B*08 generated high frequencies of corresponding $\mathrm{CD}^{+} \mathrm{T}$ cell response in blood, lymph nodes, and colon that was associated with efficient viral control. Furthermore, in two of the eight animals from the study viral rebounds during the chronic infection phase correlated with the emergence of escape variants mutated specifically in all three epitope sequences, demonstrating a direct role for $\mathrm{CD}^{+} \mathrm{T}$ cells in viral control.

The most powerful recognition for the strength of the SIV-rhesus model for HIVAIDS research comes from studies by the Sette group (Sette et al., 2005) that analyzed a panel of $\sim 900$ peptides to show a high degree of sequence homology for the Mamu-B*08-restricted epitopes from SIV to match the HIV peptide-binding motifs for HLA-B*2705 in humans, despite substantial sequence differences between these MHC alleles. Further detailed studies of the Mamu-B*08 peptide-binding motif enabled this group to identify six additional novel Mamu-B*08-restricted SIV-specific $\mathrm{CD}^{+} \mathrm{T}$ cell immune responses directed against epitopes in Gag, Vpr, and Env. This remarkable similarity of peptide-binding motifs of MHC alleles in two different species highlight not only the important role for the specific peptides and related immune responses, but also the relevance of macaques expressing such unique $\mathrm{MHC}$ alleles as model to examine EC of immunodeficiency virus replication.

One of the HIV encoded genes, nef, has long been recognized to be important for viral infectivity, though it was shown to be not required for in vitro viral replication in cell cultures. Clinical epidemiological studies identified HIV-infected asymptomatic individuals to harbor virus with mutated nef gene sequences, specifically point mutations involving the cysteine residue at position 138 (Cys-138), over a sustained period of 3 years of infection without any disease progression (Premkumar et al., 1996). Incidentally, this Cys-138 mutation in the nef gene was also identified in the chimpanzee immunodeficiency virus (CIV), another member of the lentivirus family with close similarity to HIV, but chimpanzees infected with this virus do not progress to AIDS (Premkumar et al., 1996). Furthermore, SIVagm, an SIV variant that commonly inhabits African Green monkeys expresses nef gene with multiple cysteine residues including the Cys-138 mutation, does not cause AIDS in this monkey (Premkumar et al., 1996). These observations were confirmed by experimental evidence from studies employing the SIV-rhesus model, notably by the Desrosier's group (Kestier et al., 1991) who showed that SIV variants with nef gene deletions, but not wild type SIV, failed to maintain high viral loads necessary to cause AIDS in infected adult rhesus monkeys (Kestier et al., 1991). Based on these reports, several studies explored the attenuated SIV strains with deletion of the nef gene alone or along with additional viral genes as potential candidate vaccines.
The power of non-human primates as the experimental animal models of choice for HIV-AIDS, specifically to understand the non-progression of infection/disease, extends beyond the rhesus macaques. The sooty mangabeys and African green monkeys are two non-human primate species that are the natural hosts for SIV infection where the virus exhibits high replication capacity with transient or severe $\mathrm{CD}^{+} \mathrm{T}$ cells loss but without clinical signs of simian AIDS. Valuable information has been gathered from studies in these models for SIV infection and the potential of host and viral factors to serve as correlates of protection and/or EC. In sooty mangabeys $\mathrm{CD}^{+}{ }^{+} \mathrm{CD} 4^{-} \mathrm{CD}^{-} \mathrm{T}$ cells (double-negative T cells) capable of producing Th1, Th2, and Th17 cytokines seem to partially compensate for the loss of $\mathrm{CD}^{+} \mathrm{T}$ cell function in maintaining disease-free status exemplified by controlled viral replication and low levels of immune activation (Milush et al., 2011). These studies bring to focus the importance of double-negative $\mathrm{T}$ cells and studies to better understand their modulation in HIV-AIDS (Silvestri et al., 2005; Barry et al., 2007). Similarly, studies in African green monkeys emphasize the lack of chronic $\mathrm{T}$ cell activation as a critical determinant for the difference between the non-pathogenic SIV in this model and the pathogenic HIV-1/SIV infections in humans and rhesus macaques. Accordingly, this is an active area of research pursued by several groups focusing on the innate immune system and the induction of immunosuppressive mediators, specifically during early SIV infection (Kornfeld et al., 2005; Jacquelin et al., 2009).

\section{CONCLUSION}

Non-progression to disease in HIV-infected individuals is a rare but highly important observation for designing informed and logical strategies for controlling and even preventing HIV-AIDS. Studies in the nonhuman primate models thus far revealed parallels for all stages of HIV disease progression in humans including that rare non-progression. Important lessons learned from these models included identification, with certainty, of contributing host immunological and genetic factors in more practical terms. Most significant among these are the demonstration of the relevance of $\mathrm{CD}^{+}$ T cells in controlling infection and the practical implications of protective MHC alleles, 
the later through studies demonstrating the protective efficacy of vaccine studies employing relevant SIV antigens. Similarly, studies in the natural hosts of SIV (sooty mangabeys and African green monkeys) that despite indistinguishable susceptibility to infection from experimental hosts (rhesus macaques), revealing the importance of specific immune cells subsets and chronic immune activation for LTNP. More controlled experimentation, only possible with these non-human primate animal models but not in human trials, will further help in depth understanding of these factors for designing strategies to manipulate them toward inducing desirable protective responses applicable to HIV-AIDS in humans.

\section{REFERENCES}

Barry, A. P., Silvestri, G., Safrit, J. T., Sumpter, B., Kozyr, N., McClure, H. M., et al. (2007). Depletion of CD8+ cells in sooty mangabey monkeys naturally infected with simian immunodeficiency virus reveals limited role for immune control of virus replication in a natural host species. J. Immunol. 178, 8002-8012.

Betts, M. R., Nason, M. C., West, S. M., De Rosa, S. C., Migueles, S. A., Abraham, J., et al. (2006). HIV nonprogressors preferentially maintain highly functional HIV-specific CD8+ T cells. Blood 107, 4781-4789.

Buchbinder, S. P., Mehrotra, D. V., Duerr, A., Fitzgerald, D. W., Mogg, R., Li, D., et al. (2008). Efficacy assessment of a cell-mediated immunity $\mathrm{HIV}-1$ vaccine (the Step Study): a double-blind, randomised, placebocontrolled, test-of-concept trial. Lancet 372, 1881.

Cecchinato, V., and Franchini, G. (2010). Th17 cells in pathogenic SIV infection of macaques. Curr. Opin. HIV AIDS 5, 141

Dandekar, S., George, M. D., and Bäumler, A. J. (2010). Th17 cells, HIV and the gut mucosal barrier. Curr. Opin. HIV AIDS 5, 173.

Deeks, S. G., and Walker, B. D. (2007). Human immunodeficiency virus controllers: mechanisms of durable virus control in the absence of antiretroviral therapy. Immunity 27, 406-416.

Favre, D., Lederer, S., Kanwar, B., Ma, Z.-M., Proll, S., Kasakow, Z., et al. (2009). Critical loss of the balance between Th17 and T regulatory cell populations in pathogenic SIV infection. PLoS Pathog. 5:e1000295. doi: 10.1371/journal.ppat.1000295

Fellay, J., Ge, D., Shianna, K. V., Colombo, S., Ledergerber, B., Cirulli, E. T., et al. (2009). Common genetic variation and the control of HIV-1 in humans. PLoS Genet. 5:e1000791. doi: 10.1371/journal.pgen.1000791

Freel, S. A., Lamoreaux, L., Chattopadhyay, P. K., Saunders, K., Zarkowsky, D., Overman, R. G., et al. (2010). Phenotypic and functional profile of HIVinhibitory CD8 T cells elicited by natural infection and heterologous prime/boost vaccination. J. Virol. 84, 4998-5006.

Goulder, P. J., and Watkins, D. I. (2004). HIV and SIV CTL escape: implications for vaccine design. Nat. Rev. Immunol. 4, 630-640.

Goulder, P.J. R., and Watkins, D. I. (2008). Impact of MHC class I diversity on immune control of immunodeficiency virus replication. Nat. Rev. Immunol. 8, 619-630.

Hansen, S. G., Ford, J. C., Lewis, M. S., Ventura, A. B. Hughes, C. M., Coyne-Johnson, L., et al. (2011). Profound early control of highly pathogenic SIV by an effector memory T-cell vaccine. Nature 473, 523-527.

He, H., Nehete, P. N., Nehete, B., Wieder, E., Yang, G., Buchl, S., et al. (2011). Functional impairment of central memory CD4 T cells is a potential early prognostic marker for changing viral load in SHIV-infected rhesus macaques. PLoS ONE 6:e19607. doi: 10.1371/ journal.pone.0019607

Jacquelin, B., Mayau, V., Targat, B., Liovat, A.-S., Kunkel, D., Petitjean, G., et al. (2009). Nonpathogenic SIV infection of African green monkeys induces a strong but rapidly controlled type I IFN response. J. Clin. Invest. 119, 3544.

Kalams, S. A., and Walker, B. D. (1998). The critical need for CD4 help in maintaining effective cytotoxic T lymphocyte responses. J. Exp. Med. 188, 2199-2204.

Kanwar, B., Favre, D., and McCune, J. M. (2010). Th17 and regulatory T cells: implications for AIDS pathogenesis. Curr. Opin. HIV AIDS 5, 151.

Kestier, H. W., Ringler, D. J., Mori, K., Panicali, D. L., Sehgal, P. K., Daniel, M. D., et al. (1991). Importance of the nef gene for maintenance of high virus loads and for development of AIDS. Cell 65, 651-662.

Kornfeld, C., Ploquin, M., Pandrea, I., Faye, A., Onanga, R., Apetrei, C., et al. (2005). Antiinflammatory profiles during primary SIV infection in African green monkeys are associated with protection against AIDS J. Clin. Invest. 115, 1082-1091.

Loffredo, J. T., Bean, A. T., Beal, D. R., León, E. J., May, G. E., Piaskowski, S. M., et al. (2008). Patterns of CD8+ immunodominance may influence the ability of Mamu-B* 08-positive macaques to naturally control simian immunodeficiency virus SIVmac239 replication. J. Virol. 82, 1723-1738.

Mercier, G. T., Nehete, P. N., Passeri, M. F., Nehete, B. N., Weaver, E. A., Templeton, N. S., et al. (2007). Oral immunization of rhesus macaques with adenoviral HIV vaccines using enteric-coated capsules. Vaccine 25, 8687-8701.

Migueles, S. A., Sabbaghian, M. S., Shupert, W. L. Bettinotti, M. P., Marincola, F. M., Martino, L., et al. (2000). HLA B* 5701 is highly associated with restriction of virus replication in a subgroup of HIV-infected long term nonprogressors. Proc. Natl. Acad. Sci. U.S.A. 97, 2709-2714.

Milush, J. M., Mir, K. D., Sundaravaradan, V., Gordon, S. N., Engram, J., Cano, C. A., et al. (2011). Lack of clinical AIDS in SIV-infected sooty mangabeys with significant CD4+ T cell loss is associated with doublenegative T cells. J. Clin. Invest. 121, 1102.

Mudd, P. A., Martins, M. A., Ericsen, A. J., Tully, D. C., Power, K.A., Bean,A. T., et al. (2012). Vaccine-induced
CD8+ T cells control AIDS virus replication. Nature 491, 129-133.

Nehete, P. N., Chitta, S., Hossain, M. M., Hill, L., Bernacky, B. J., Baze, W., et al. (2001). Protection against chronic infection and AIDS by an HIV envelope peptidecocktail vaccine in a pathogenic SHIV-rhesus model. Vaccine 20, 813-825.

Nehete, P. N., Lewis, D. E., Tang, D. N., Pollack, M. S., and Sastry, K. J. (1998). Presence of HLA-C-restricted cytotoxic T-lymphocyte responses in long-term nonprogressors infected with human immunodeficiency virus. Viral Immunol. 11, 119-129.

Nehete, P. N., Nehete, B. P., Hill, L., Manuri, P. R. Baladandayuthapani, V., Feng, L., et al. (2008). Selective induction of cell-mediated immunity and protection of rhesus macaques from chronic SHIVKU2 infection by prophylactic vaccination with a conserved HIV-1 envelope peptide-cocktail. Virology 370, 130.

Nehete, P. N., Nehete, B. P., Manuri, P., Hill, L., Palmer, J. L., and Sastry, K. J. (2005). Protection by dendritic cells-based HIV synthetic peptide cocktail vaccine: preclinical studies in the SHIV-rhesus model. Vaccine 23, 2154-2159.

Premkumar, D. R., Ma, X.-Z., Maitra, R. K., Chakrabarti, B. K., Salkowitz, J., Yen-Lieberman, B., et al. (1996). The nef gene from a long-term HIV type 1 nonprogressor. AIDS Res. Hum. Retroviruses 12, 337-345.

Saksena, N. K., Rodes, B., Wang, B., and Soriano, V. (2007). Elite HIV controllers: myth or reality. AIDS Rev. 9, 195-207.

Sette, A., Sidney, J., Bui, H.-H., del Guercio, M.-F., Alexander,J.,Loffredo, J., et al. (2005). Characterization of the peptide-binding specificity of Mamu-A* 11 results in the identification of SIV-derived epitopes and interspecies cross-reactivity. Immunogenetics 57 , 53-68.

Silvestri, G., Fedanov, A., Germon, S., Kozyr, N., Kaiser, W. J., Garber, D.A., et al. (2005). Divergent host responses during primary simian immunodeficiency virus SIVsm infection of natural sooty mangabey and nonnatural rhesus macaque hosts. J. Virol. 79, 4043-4054.

Weaver, E. A., Nehete, P. N., Nehete, B. P., Buchl, S. J., Palmer, D., Montefiori, D. C., et al. (2009). Protection against mucosal SHIV challenge by peptide and helper-dependent adenovirus vaccines. Viruses 1 , 920-938.

Received: 26 February 2013; accepted: 28 February 2013; published online: 13 March 2013.

Citation: Nehete PN, Singh S and Sastry KJ (2013) Lessons on non-progression of HIV disease from monkeys. Front. Immunol. 4:64. doi: 10.3389/fimmu.2013.00064

This article was submitted to Frontiers in HIV and AIDS, a specialty of Frontiers in Immunology.

Copyright $(2013$ Nehete, Singh and Sastry. This is an openaccess article distributed under the terms of the Creative Commons Attribution License, which permits use, distribution and reproduction in other forums, provided the original authors and source are credited and subject to any copyright notices concerning any third-party graphics etc. 